\title{
IMPLEMENTING THE LEARNER-CENTERED DESIGN PARADIGM FOR WEB-BASED TRAINING CURRICULA
}

\author{
Panagiotis Zaharias and Angeliki Poulymenakou \\ Athens University of Economics \& Business, Greece
}

\begin{abstract}
Learning environments provide exciting possibilities for learning and training, but dropout rates are high and the quality of e-Learning courses is being questioned. Capturing requirements, and developing usable e-learning courses, focusing on usability and user-centred design are of high importance. Such efforts must be redefined for e-learning contexts. This paper stresses the need for usable and effective e-learning design and describes the authors' experience in adapting methods and techniques of human-centred design implementing a learner-centred approach to the design e-Learning.
\end{abstract}

Key words: design-technology, learner-centred design, learning materials

\section{INTRODUCTION}

e-Learning environments and courses provide exciting possibilities for supporting a wide spectrum of learners: students in schools and universities, business professionals seeking new training experiences, adult learners in general under the lifelong learning context. However, the focus of eLearning is often far more on technology issues and not on the quality of learning-focus on the ' $e$ ' and not on 'learning'-with techno-centric design (Lohr, 2000) being the dominant approach. As a consequence dropout rates are high and this is a serious concern (Murray, 2001; Diaz, 2002). Figures on the dropout rates for e-learning courses vary; it is estimated that between $30-75 \%$ of students fail to complete e-learning courses (Ganzel, 2001). 
The poor design of e-learning courses is a basic reason for the dropout rates. Poor usability compounds this attrition problem by causing frustration or creating unnecessary barriers to completing e-learning courses (Notess, 2001). Usability can play a key role in creating a positive user experience; usability is not an add-on feature but must be built-in (Nielsen, 1994; Shneiderman, 1998; Maguire, 2001). To ensure the latter, the human-centred design paradigm (HCD) must be adopted for e-Learning design.

This paper describes the authors' efforts to adjust the methods and techniques of HCD to e-learning projects (a web-based training curriculum) thus implementing a learner-centred design. The TrainSEE project (Zaharias and Poulymenakou, 2003a) provides the context for our work. It is an elearning project aiming at enhancing ICT skills in South-Eastern (SE) European countries. The determination of the ICT skills and competencies to be offered, and hence the creation of the corresponding e-learning service (web courses), is guided by the Generic Skills Profiles for the ICT Industry in Europe (www.career-space.com). The following sections describe the authors' experiences in the design and development of the web courses for the TrainSEE project.

\section{LEARNER-CENTERED DESIGN OF WEB- BASED TRAINING COURSES}

HCD is concerned with incorporating the user's perspective into the software development process in order to achieve a usable system (ISO, 1999). User-centred design is a process of integrating user requirements, user interface validation, and testing into standard software design methods. It views knowledge about users and their involvement in the design process as a central concern (Preece et al., 1994). These two terms are now used interchangeably. Focusing on HCD means involving users in the process of designing a particular product, understanding their needs, and addressing them in very specific ways (Maguire 2001). Our main concern was to involve trainees early in the design process in an active way that would engage them, thus helping the designers to design a learner-centred elearning service. Nevertheless, we had to make adjustments since the elearning projects have their own difficulties and particularities: learners have their own special needs and they differ from the typical users of software applications. Smulders (2002) reflects on the 'double persona' of the learneruser duopoly. In addition, learning is a quite different task from those that typical software users have to perform. Learning cannot be approached as a conventional task, as though it was just another kind of work, with a number 
of problems to be solved and various outputs to be produced (Mayes and Fowler, 1999).

The following describes our efforts to adapt the methods and techniques of HCD and web-based instructional design to an e-learning project. The structure of the description is provided by Maguire (2001) who identifies the five essential processes that should be undertaken in order to incorporate ISO 13407 usability requirements into the software development process. These are described below. It has to be clear that these steps are not necessarily linear in sequence. Rather than that many sub-activities can go in parallel and the whole learner-centred design is an iterative process.

\subsection{Plan the human (learner) centred design process}

The aim in the first phase - usability planning and scoping, is to bring together the several stakeholders to discuss the project objectives and to create a vision of how a learner-centred design approach and usability considerations can contribute to the project's objectives. They also served to identify the stakeholders. During this phase several meetings of representatives of all of the stakeholders were held. Some of the main issues were the project's overall objective, the user organizations and their needs, the trainees and their profiles and technical and environmental constraints.

\subsection{Understand and specify the context of use}

This stage involved:

- Surveying the general characteristics of trainees: Since the trainee population was diverse and geographically dispersed, we distributed a survey through email and asked the heads of the trainees in each user organization to provide us with a generic description of the trainees' background, academic education, skills, main job-related responsibilities as well as an estimation of the number of trainees that will use the elearning service of TrainSEE project.

- Task Analysis: Methods and tools from instructional design practice were used to perform this activity (Nelson et al., 1995). Task analysis is used to determine the knowledge, skills, tools and requirements needed to perform a job; it goes in parallel with training needs assessment. During this phase a combination of data gathering methods such as interviews and surveys were used. This facilitates the task of developing the most appropriate training materials and content. Only tasks that had a perceived high performance gap (Zaharias \& Poulymenakou, 2003a) were selected. 


\subsection{Specify the user and organizational requirements}

This involves a number of stages as described below:

- Existing system/ competitor analysis: an informal analysis of existing elearning courses on ICT topics and e-learning authoring tools was conducted. This process although conducted in an unstructured way provided significant input for the design of the web-based courses, especially for usability problems' identification.

- Focus group: a focus group was organized that brought together five trainees and their supervisor representing one user organization, and members of the design team. During this focus group a brief introduction of the main concepts of the project was given. The first part of the focus group was accompanied by further discussion focused on prior training experiences of the trainees, their special ways of learning, their opinions and attitudes towards web-based training methods and their expectations regarding the TrainSEE e-learning service and web courses. The second part of the focus group included a short presentation about the learning environment (selected in the previous phase) where the web courses would be uploaded; additionally an early prototype of the web courses was presented. Actually this was an effort to initiate a participatory kind of evaluation known as evaluation walkthrough. The presentation was a process of going step-by-step through the web courses and the e-learning environment aiming at receiving feedback from the stakeholders (in that case the trainees' supervisor) and the trainees themselves.

- User requirements: these were captured by two sets of activities:

- Trainee-level requirements: A survey was used as the main source for capturing information along a wide spectrum of variables that affect successful implementation of learning applications: a) Trainees' learning styles and preferences, b) Trainees' motivation (extrinsic) for taking the web courses, c) Trainees' special ways of learning (learning habits), d) Trainees' attitude towards several training methods and e) Trainees' past training experiences. Interpretation of the results was facilitated by the relevant literature (Kolb,1984; Honey and Mumford, 1992).

- Organizational-level requirements: This activity was quite critical; a framework for training needs assessment (Ostroff and Ford, 1989) was followed that facilitated the identification of the organizationallevel requirements in terms of training needs of each user organization. This framework combines the dual perspectives of content (person, task, organizational) and levels (individual, subunit and organizational). 
This systematic approach (including organizational dimension) was considered essential in our case, since the e-learning service is a new experience for the user organizations. The methodology for conducting training needs assessment was basically guided by a) Content levels framework (Ostroff and Ford, 1989) and b) Generic Skills Profiles for the ICT Industry in Europe (Career Space project, 2000). In this phase questionnaires and interviews were used as main instruments for data collection. The main result of this phase was the selection of two broad areas of skills and competencies that the web-based courses had to address: a) S/W \& Applications Development and b) IT Business Consultancy. More details for these two broad areas of skills and competencies and the relevant task and job analysis can be found in Zaharias and Poulymenakou (2003a).

\subsection{Design}

- Design guidelines: Our initial design efforts included a thorough review process of web design guidelines (Nielsen, 2000b; Lynch and Horton, 1997) and Instructional Design guidelines and frameworks (Weston et al., 1999; Johnson and Aragon, 2002) in order to effectively integrate web design and instructional design guidelines. Individual differences, motivation, information and cognitive overload, consistency, navigation support, online help and documentation and adult learning principles were also considered in the interface design process.

- Storyboarding: Storyboards are sequences of images that show the relationship between user actions and system outputs (Nielsen, 1991). They were developed to gather information regarding the structure, functionalities and navigational options of web courses. They were used as a basis for initiating constructive discussions among the members of the design and development team and the subject matter experts.

- Software prototype: A software prototype exhibited the interface and actual content of two learning modules. It was a high fidelity prototype as most of the functionalities were incorporated, whose purpose was to have a small set of trainees interact with a more realistic subset of the learning application. Trainees were asked to freely explore the software prototype; no specific tasks or scenarios for interaction were given at this phase. The trainees were interviewed about their experience with the web courses. Questions focused on the course content and its relevance to the trainees' needs and job tasks, the difficulty level of the courses, navigation through the courses, the interactivity level, the clarity of learning objectives and their general impressions of the course. 


\subsection{Evaluation}

Evaluation is a critical phase for our work and it is focused on gathering as much qualitative and quantitative information from the stakeholders especially from the trainees themselves. Usability and its testing were the main pillars in our evaluation activities. Usable learning environments and courses are supposed to contribute to educational and training goals (Jones et al., 1999). Usability testing can have a significant impact on the instructional product development cycle as well as the instructional systems design process (Lee, 1999). Our evaluation plan consists of five steps:

1. Evaluation walkthrough: The first step towards evaluation of the design was the evaluation walkthrough as described in focus group section.

2. Interaction with software prototype: The second step was set up by having five trainees interact with the software prototype. This was accompanied by interviews as described in the previous section.

3. Content quality control: Five subject matter experts were involved in this evaluation activity. A short checklist focusing on quality of instructional content and materials was created by the instructional designer (member of the design and development team) and used by the evaluators.

4. Heuristic evaluation: This is an expert-based inspection of the courses. Design changes have been made based on the recommendations of two expert evaluators, Given the time constraints the redesign focused only on the most severe usability problems.

5. Usability testing: a sample of trainees will perform a number of tasks while interacting with the courses. The tasks are based on training needs assessments and task analysis, trainees' learning styles and preferences and the instructional strategy used throughout the course. This occurs in the user organization's environment to ensure that the testing will occur under conditions close to the "real" ones. It will be accompanied by interviews and satisfaction questionnaires.

The heuristic evaluation has been completed while the usability testing is forthcoming. Evaluating e-Learning 'may move usability practitioners outside their comfort zone' Notess (2001) since they need to familiarize themselves with learning theories, evaluation frameworks and instructional design methods. Problems emerged in the heuristic evaluation: the experts have expertise in the human factors area but they had difficulties when trying to interpret the heuristics for learning and instructional design. Also, difficulties arose when trying to define a set of 'representative tasks' for the usability test. Researchers and practitioners have to be aware of the difficulty of defining and measuring learning and relevant tasks; they must also refine the current usability evaluation methods since there is a scarcity of such methods customized for e-Learning. 


\section{CONCLUSION AND FUTURE RESEARCH}

We discussed how the learner-centered design paradigm can be realized to ensure quality in e-learning experiences. Capturing requirements, designing and developing usable e-learning courses, focusing on usability and iterative design are of high importance. Special attention must be paid on the specificities of e-learning projects; learner (and e-learner) is not a typical type of software user. Learning is not a conventional type of task. Future research needs to focus on such specificities: new frameworks for capturing e-learning requirements are needed, usability and its dimensions must be refined to fit in e-learning context, new usability evaluation techniques have to emerge combining usability, learning theories, and instructional design guidelines. Research efforts must be initiated, supported and empirically validated. The results are expected to shed light onto the most neglected parts of e-learning: enhancing the 'learning' rather than ' $e$ '.

\section{REFERENCES}

Career Space project, (2000). Software \& Applications Development job profile. Available at http://www.career-space.com/downloads/index.htm

Diaz, D. P. (2002). Online Drop Rates Revisited. The Technology Source, May/June 2002. Available at http://ts.mivu.org/default.asp?show=article\&id=981

Ganzel, R. (2001). Associated Learning, Online Learning Magazine, May. Available at $\mathrm{http}: / / \mathrm{www}$. onlinelearningmag.com/

Honey, P., \& Mumford, A. (1992). The manual of learning styles. Maidenhead: Peter Honey ISO (1999). Human-centred design processes for interactive systems. Geneva: ISO

Johnson S., \& Aragon S. (2002). An Instructional Strategy Framework for Online Learning Environments. In proceedings of World Conference on E-Learning in Corporate, Government, Healthcare \& Higher Education, (pp. 529-536). Norfolk, VA: AACE

Jones, A. et al. (1999). Contexts for evaluating educational software, Interacting with Computers 11 (5) 499-516

Kolb, D. A. (1984). Experiential learning. Englewood Cliffs, N.J.: Prentice-Hall

Lee, S. H., (1999). Usability Testing for Developing Effective Interactive Multimedia Software: Concepts, Dimensions, and Procedures. Educational Technology and Society, 2(2), 20-29.

Lohr. L L. (2000). Designing the instructional interface. Computers in Human Behaviour. 16 161-182.

Lynch, P. J., \& Horton, S. (1997). Web Style Guide Basic Design Principles for Creating Web sites. Yale University Press. Available http://www.info.med.yale.edu/caim/manual

Maguire M. (2001). Methods to support human-centred design. International Journal of Human-Computer Studies, 5, 587-634.

Mayes. J. T., \& Fowler C. J. (1999). Learning technology and usability: a framework for understanding courseware, Interacting with Computers 11(5) 485-497.

Murray, B. (2001). What Makes Students Stay? ACM eLearn Magazine. (May). Available at http://www.elearnmag.org/ 
Nelson, R. R., Whitener, E. M., \& Philcox, H. H., (1995). The Assessment of End-User Training Needs. Communications of the ACM, 38(7), 27-39.

Nielsen, J. (2000). Designing web usability: The practice of simplicity. Indianapolis: New Riders Publishing.

Nielsen, J. (1994). Heuristic evaluation. In J. Nielsen \& R. Mack (Eds.), Usability inspection methods. New York: John Wiley \& Sons.

Nielson, J. (1991). Paper versus computer implementations as mock up scenarios for heuristic evaluation. In D. Diaper, et al.(Eds), Proceedings of the IFIP Third International Conference on Human-Computer Interaction (pp. 315-320). Amsterdam: North-Holland

Notess, M. (2001). Usability, User Experience, and Learner Experience. ACM eLearn Magazine. [Tutorial]. Available at http://www.elearnmag.org/

Ostroff, C. and Ford, J. K. (1989). Assessing training needs: Critical levels of analysis. In Training and Development in Organizations. Jossey-Bass, San Francisco, 1989, 25-62

Preece, J., Rogers, Y., Sharp, H. et al., (1994). Human-computer interaction, Workingham, England: Addison-Wesley.

Shneiderman, B. (1998). Designing the user interface: Strategies for effective HumanComputer Interaction. ( $3^{\text {rd }}$ edition). Addison Wesley.

Smulders, D., (2002). Designing for Learners, Designing for Users. ACM eLearn Magazine. Available at http://www.elearnmag.org/subpage/sub_page.cfm?section=3 /

Weston, C., Gandell, T., McApline, L., and Filkenstein, A. (1999). Designing Instruction for the Context of Online Learning, The Internet and Higher Education 2(1), 35-44

Zaharias, P., Poulymenakou, A. (2003a). Identifying training needs for ICT skills enhancement in South-Eastern Europe: Implications for designing web-based training courses Educational Technology \& Society, 6 (1). Available at http://ifets.ieee.org

\section{BIOGRAPHY}

Panagiotis Zaharias has research interests in the design and usability evaluation of e-learning courses (mainly asynchronous, self-paced web courses) and technologies. Angeliki Poulymenakou has research interests in the organizational and social implications of elearning and knowledge management implementation.

\section{ACKNOWLEDGEMENTS}

TrainSEE is funded by the European Commission's Information Society Technologies (IST) programme. We wish to acknowledge INTRASOFT International, Open University of Catalonia, Lambrakis Research Foundation, Athens University of Economics and Business, Public Power Company of Greece, Bulgarian Telecommunications Company, LOGO Business Solutions, National Oil Company PETROM, IBM Central and Eastern Europe/Middle East/Africa Inc, Bulgarian Academy of Science, and ISIK University. 